\title{
Effect of glass fibre grids on the bonding strength between two asphalt layers
}

L. Sagnol

ICUBE, UMR 7347, CNRS, INSA de Strasbourg, Strasbourg, France

Institut Grund- und Straßenbau, Hochschule Karlsruhe Technik und Wirtschaft, Karlsruhe, Germany

C. Chazallon

ICUBE, UMR 7347, CNRS, INSA de Strasbourg, Strasbourg, France

M. Stöckner

Institut Grund- und Straßenbau, Hochschule Karlsruhe Technik und Wirtschaft, Karlsruhe, Germany

\begin{abstract}
The study evaluates the effect of glass fibre grids, used to reinforce asphalt structures, on the bonding strength between a wearing and a binder course. For this purpose, a test surface consisting of a $6 \mathrm{~cm}$ thick binder $(0 / 16 \mathrm{~mm})$ and a $6 \mathrm{~cm}$ thick wearing course $(0 / 10 \mathrm{~mm})$ was built. Four different grids coated with various quantities of the bitumen emulsions C60B4-S and C40B5-S were used. Comparison sections were made without grid but also coated with different quantities of emulsions. Extracted cores with a $150 \mathrm{~mm}$ diameter were tested at ambient laboratory temperature with a monotonous shear test (LEUTNER). Displacement, shear force and shear stress were measured. The influence of grid characteristics, the existence of a nonwoven and the size of the strands as well as the effect of different emulsions on the shear bonding strength were observed. We find that the tests without a reinforcement grid reach more important values of stress at failure and that the decrease in shear stress levels at failure is more important for bigger grid sections.
\end{abstract}

\section{INTRODUCTION}

The increase of traffic intensity and load in the past decades has led to the development of new economical and environmentally friendly maintenance methods. Interlayer reinforcement products as glass fibre grids have in recent years gained in importance in this field, and their benefits have been proved in various studies in the prevention of reflective cracking and in the prolongation of service life of asphalt pavements (Arsenie et al. 2016)(Nguyen et al. 2013)(Nejad et al. 2014). However it is also known that the insertion of grids at the interlayer can lead to a reduction of bonding (Vismara et al. 2012) (Sokolov 2007), which can be critical for the transfer of shear stresses into the pavement structure. This article describes the influence of grid and coating characteristics on the bonding between an asphaltic wearing course and a binder course. In an experimental part, monotonous shear tests on samples reinforced with different grids, different emulsions as well as different emulsion application rates have been compared, especially using over- and underdosages compared to recommended rates.

\section{MATERIAL AND SAMPLE PREPARATION}

For the construction of the samples an asphaltic double layer outdoor test surface ( $5 \mathrm{~m}$ by $22 \mathrm{~m}$ ) consisting of a $6 \mathrm{~cm}$ thick $0 / 16$ binder course with 25/55-55 RC bitumen and a $6 \mathrm{~cm}$ thick $0 / 11$ wearing course with 25/55-55 A bitumen was built on an unbound granular base course. The heights of the courses were chosen to guaranty the minimal height of $4 \mathrm{~cm}$ per course required for the LEUTNER shear test.

The test surface was divided in 28 sections, partly reinforced by 4 grids, coated with 2 different emulsions and 3 to 4 different application rates. The grids were inserted between the binder and the wearing course.

The characteristics of the four grids and the emulsions used in this study are shown in table 1 and 2 .

Table 1. Characteristics of the grids installed on the test surface

\begin{tabular}{lllll}
\hline $\begin{array}{l}\text { Grid } \\
\text { Name }\end{array}$ & Non-woven & Resin & $\begin{array}{l}\text { Tensile } \\
\text { strength }\end{array}$ & $\begin{array}{l}\text { Mesh } \\
\text { size }\end{array}$ \\
\cline { 3 - 5 } & & $\mathrm{kN} / \mathrm{m}$ & $\mathrm{cm}^{2}$ \\
\hline 1 & Light polyester fibre & A & 100 & $4 \times 4$ \\
\hline 5 & Light polyester fibre & A & 50 & $4 \times 4$ \\
\hline W & - & A & 50 & $4 \times 4$ \\
\hline $\mathrm{N}$ & Light polyester fibre & B & 50 & $4 \times 4$ \\
\hline
\end{tabular}


Table 2. Characteristics of the emulsions applied on the test surface

\begin{tabular}{lll}
\hline Emulsion & C40B5-S & C60B4-S \\
\hline Content of residual binder [\%] & 40 & 60 \\
\hline Breaking value & $>180$ & 122 \\
\hline Needle penetration $[0,1 \mathrm{~mm}]$ & 100 & 172 \\
\hline Softening point Ring and Ball $\left[{ }^{\circ} \mathrm{C}\right]$ & 46.2 & 42.8 \\
\hline $\begin{array}{l}\text { Fluxing agent to reduce the viscosi- } \\
\text { ty [\%] }\end{array}$ & 2 to 3 & $<2$ \\
\hline
\end{tabular}

The emulsions were applied with spray diffuser and painter rolls for the large application rates and with brushes for the smaller application rates. The grids were applied on the unbroken emulsion and pressed on the structure with brooms until the grids and their non-woven were blackened with the emulsion.

The application rates were varied depending on the grid used in each section, aiming for under- und over-dosages of the reinforced sections. The application rates used for the unreinforced sections are based on the instructions given in the German directive ZTV Asphalt-StB 2013 (ZTV 2013) except for the section 600 . The application rates used in this study are listed in table 3 . The recommended application rates of the reinforced sections were given by the manufacturer of the grids.

The name of each section is based on the applied emulsion (4 for C40B5-S and 6 for C60B4-S) as first number, the grid $(0-$ no grid, $1,5, \mathrm{~W}$ and $\mathrm{N})$ as second and the emulsion application rate number 0 (highest) to 3 (lowest) as third number. All sections with the same grid and the same emulsion are summarized as section group and have an $\mathrm{X}$ instead of an application rate number.

Table 3. Sections built for the study and their characteristics

\begin{tabular}{|c|c|c|c|c|}
\hline $\begin{array}{l}\text { Name } \\
\text { of the } \\
\text { sections }\end{array}$ & Emulsions & Grids & $\begin{array}{l}\text { Application } \\
\text { rate } \\
\text { residual } \\
\text { binder } \\
\mathrm{g} / \mathrm{m}^{2}\end{array}$ & $\begin{array}{l}\text { Recommended } \\
\text { application } \\
\text { rate (residual } \\
\text { binder) } \\
\mathrm{g} / \mathrm{m}^{2}\end{array}$ \\
\hline $\begin{array}{l}600 \\
601 \\
602 \\
603\end{array}$ & C60B4-S & $\begin{array}{l}\text { Reference } \\
\text { structure, } \\
\text { no grid }\end{array}$ & $\begin{array}{l}816 \\
210 \\
150 \\
90\end{array}$ & $90-150$ \\
\hline $\begin{array}{l}610 \\
611 \\
612 \\
613\end{array}$ & C60B4-S & 1 & $\begin{array}{l}600 \\
420 \\
360 \\
300\end{array}$ & 600 \\
\hline $\begin{array}{l}650 \\
651 \\
652 \\
653 \\
\end{array}$ & C60B4-S & 5 & $\begin{array}{l}1636 \\
360 \\
300 \\
240 \\
\end{array}$ & 500 \\
\hline $\begin{array}{l}6 \mathrm{~W} 1 \\
6 \mathrm{~W} 2 \\
6 \mathrm{~W} 3\end{array}$ & C60B4-S & W & $\begin{array}{l}270 \\
210 \\
150\end{array}$ & 350 \\
\hline $\begin{array}{l}401 \\
402 \\
403\end{array}$ & C40B5-S & $\begin{array}{l}\text { Reference } \\
\text { structure, } \\
\text { no grid }\end{array}$ & $\begin{array}{l}140 \\
100 \\
60\end{array}$ & $80-120$ \\
\hline
\end{tabular}

\begin{tabular}{lllll}
\hline 411 & & & 280 & - \\
412 & C40B5-S & 1 & 240 & \\
413 & & & 200 & - \\
\hline 451 & & & 240 & \\
452 & C40B5-S & 5 & 200 & - \\
453 & & & 180 & \\
\hline $4 \mathrm{~W} 1$ & & & 180 & \\
$4 \mathrm{~W} 2$ & $\mathrm{C} 40 \mathrm{~B} 5-\mathrm{S}$ & $\mathrm{W}$ & 140 & - \\
$4 \mathrm{~W} 3$ & & & 100 & \\
\hline $4 \mathrm{~N}$ & $\mathrm{C} 40 \mathrm{~B} 5-\mathrm{S}$ & $\mathrm{N}$ & 200 & - \\
\hline
\end{tabular}

For each section, nine cores with a $150 \mathrm{~mm}$ diameter were extracted and five to six of them were tested, except for the sections 412, 451 and 4W3 which had only four samples tested as all other cores broke during drilling. A total of 228 cores were extracted.

\section{MONOTONOUS SHEAR TEST: LEUTNER TEST}

\subsection{Method}

The LEUTNER shear test is a destructive monotonous shear test with pure interlayer shearing. These tests were performed according to the German directive TP Asphalt StB Teil 80 - Abscherversuch 2012 (TP-A 2012), except for the test temperature which was taken at laboratory conditions at $(25 \pm 3)$ ${ }^{\circ} \mathrm{C}$. During the test, the binder course of the core was fixed while the wearing course was loaded with a constant shear displacement rate of $50 \mathrm{~mm} / \mathrm{min}$ until failure occurred. The displacement, shear force and shear stress were measured during the tests.

\subsubsection{Temperature adjustment}

In order to enable the comparison of the shear stress results, the temperatures of the different tests were analytically adjusted to $(25 \pm 1){ }^{\circ} \mathrm{C}$ using the relation proposed by Canestrari et al. (Canestrari et al. 2012) represented by the equation:

$$
\tau=10^{\left(a^{*} T+b\right)}
$$

where $\tau$ is the maximum shear stress in $\mathrm{MPa}, \mathrm{T}$ the temperature in ${ }^{\circ} \mathrm{C}$ and $\mathrm{a}, \mathrm{b}$ coefficients.

The coefficients $a$ and $b$ required for our sections were determined using the shear-test results of Vismara et al. (Vismara et al. 2012) carried out with glass fibre reinforced and unreinforced specimens (made of two layers of $\mathrm{AC} 0 / 11$ ) at $5{ }^{\circ} \mathrm{C}$ and $25^{\circ} \mathrm{C}$ and are as followed:

- For unreinforced specimens: $\mathrm{a}=-0.03407$ and $b=0.91585$

- For reinforced specimens: $a=-0.0374$ and $b$ $=0.4424$

Results of tests performed at $(25 \pm 1){ }^{\circ} \mathrm{C}$ remained unchanged, the other tests were adjusted using these equations. 


\subsection{Results}

The maximum average shear stresses achieved by each section for a given quantity of residual binder are shown in figure 1 . The grey curves represent the sections coated with C40B5-S while the black curves the sections coated with C60B4-S.

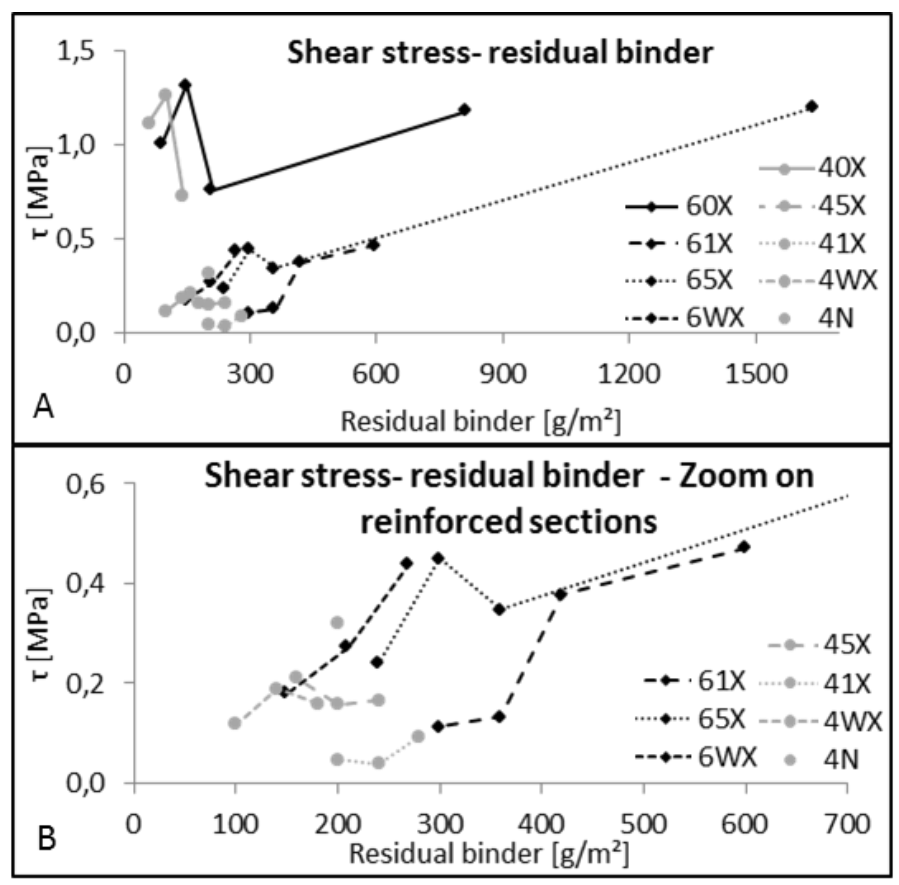

Figure 1. Average maximum shear stresses against residual binder application rates. A: All results with standard deviation; B: Zoom on reinforced sections

\subsubsection{Influence of the grid}

As can be observed on figure 1A, every reinforced section except the strongly overdosed section 650 reach lower maximum shear stresses than the unreinforced section groups $40 \mathrm{X}$ and $60 \mathrm{X}$. These results confirm previous studies of Vismara et al. (Vismara et al. 2012) and Sokolov (Sokolov 2007) about the negative influence of the insertion of grids on the bonding in an asphalt pavement structure.

\subsubsection{Influence of the residual binder application rate}

The observations made on the influence of the application rate can be divided in three points: influence on reinforced sections with low application rates (1 to 3 ), influence on all reinforced sections (application rates 0 to 3 ) and influence on unreinforced sections.

The first observation made on reinforced section with low application rates of residual binder (from $100 \mathrm{~g} / \mathrm{m}^{2}$ to about $400 \mathrm{~g} / \mathrm{m}^{2}$ ) shows no clear tendency. Only the group 6WX, without non-woven, shows a relatively linear curve representing an increase of the maximum shear stress with more residual binder. The curve $613,-2,-1$ also shows an increase, however in a far less linear way. The curves $653,-2,-1$ and $4 \mathrm{~W} 3,-2,-1$ show peaks while the curves $413,-2,-1$ and $453,-2,-1$ have a flat tendency.
When looking on the curves of section groups $65 \mathrm{X}$ and $61 \mathrm{X}$, including the points 650 (strongly overdosed) and 610 (coated with recommended amount), we observe a tendency for greater shear stress results with greater application rates. This tendency is also visible in their linear correlation coefficients, being of 0.99 for $65 \mathrm{X}$ and 0.91 for $61 \mathrm{X}$. $6 \mathrm{WX}$ has also a nearly perfect linear correlation coefficient of 0.99 .

The comparison of the reinforced sections with low application rates with the complete reinforced sections leads to the assumption that low quantities of residual binder applied on sections with grids with non-woven have no improvement effect on the bonding. The quantity from which the bonding is improved seems not to be reached for the C40B5-S coated sections. It can be assumed that the required minimum quantity is depending on the thickness and the absorbability of the non-woven. We can also observe on section 650 that, for a great amount of emulsion (here $1636 \mathrm{~g} / \mathrm{m}^{2}$ ), a reinforced section can achieve maximum shear stresses comparable to the best results of the unreinforced sections.

The addition of residual binder on unreinforced specimens causes at first an increase in bonding until the second application rate. From this peak, the shear stresses decrease again. This effect is mostly explained through the creation of a slip plane caused by a surplus of residual binder, as described by Canestrari et al. (Canestrari et al. 2012). However the shear stress of section 600, having an application rate of $816 \mathrm{~g} / \mathrm{m}^{2}$, reaches an average value comparable to the value of 602 .

\subsubsection{Influence of the emulsion type}

We observe that the curves $40 \mathrm{X}$ and 60X, having the same emulsion application rate but different residual binder quantities, reach similar maximum shear stresses and show similar curve progressions from application rate 3 to application rate 1 , although emulsion C40B5-S has a lower residual binder content, but firmer bitumen and more fluxing agent (see table 2). When looking on the reinforced sections, we can see that the results of the C40B5-S coated sections are lower than the results of C60B4$\mathrm{S}$ coated sections. Here the firmer bitumen and fluxing agent of C40B5-S are not enough to overcome the lower residual binder content.

\subsubsection{Influence of the non-woven}

The grids $\mathrm{W}$ and 5 differ from each other only by the existence of a light non-woven between the strands of grid 5, while grid $\mathrm{W}$ has none. Figure 2A shows that for the same quantity of residual binder the results of the grid $\mathrm{W}$ are higher than of grid 5. It can therefore be assumed that the existence of a light non-woven between the strands has a low negative effect on the bonding. 


\subsubsection{Influence of the resin}

The grids 5 and $\mathrm{N}$ differ only in the resin used to coat and protect the glass fibre of the grid. For grid $\mathrm{N}$, only the emulsion C40B5-S with an application rate of $200 \mathrm{~g} / \mathrm{m}^{2}$ of residual binder was tested. This section can directly be compared with section 452 , also coated with $200 \mathrm{~g} / \mathrm{m}^{2}$ of residual binder of C40B5-S. As showed in figure $2 \mathrm{~B}$, we can observe that the shear stress results of section $4 \mathrm{~N}$ are largely higher than those of section 452. Further, on figure 1B (zoom on reinforced samples), we can observe that the grid $\mathrm{N}$ reaches the highest shear stresses of all reinforced C40B5-S coated sections as well as the better results of C60B4-S coated sections with the same or similar quantity of residual binder.

\subsubsection{Influence of the shape of the strands}

$3 \mathrm{D}$-scans of the strands of the grids were made in order to analyse their shapes. For this examination, nine strands of each grid direction (machine direction "md" or warp yarn and cross machine direction "cmd" or filling yarn) of the grids N, 5 (same as W) and 1 were scanned with a 3D-microscop. The average shape of each strand can be seen in figure $2 \mathrm{C}$.

We observe that the strands of the grid 1, having a tensile strength twice as high as 5 and $\mathrm{N}$, are nearly twice as wide as the grids 5 and $\mathrm{N}$, without being noticeably higher than the two other grids.

The comparison of the strands of the grids 5 and $\mathrm{N}$ shows that the strands of the grid $\mathrm{N}$ are slightly taller but also slightly thinner than the strands of the grid 5, which can lead to a better interlocking with the granular of the upper layer, explaining partly the better results of $4 \mathrm{~N}$ comparing to 452 as discussed before.

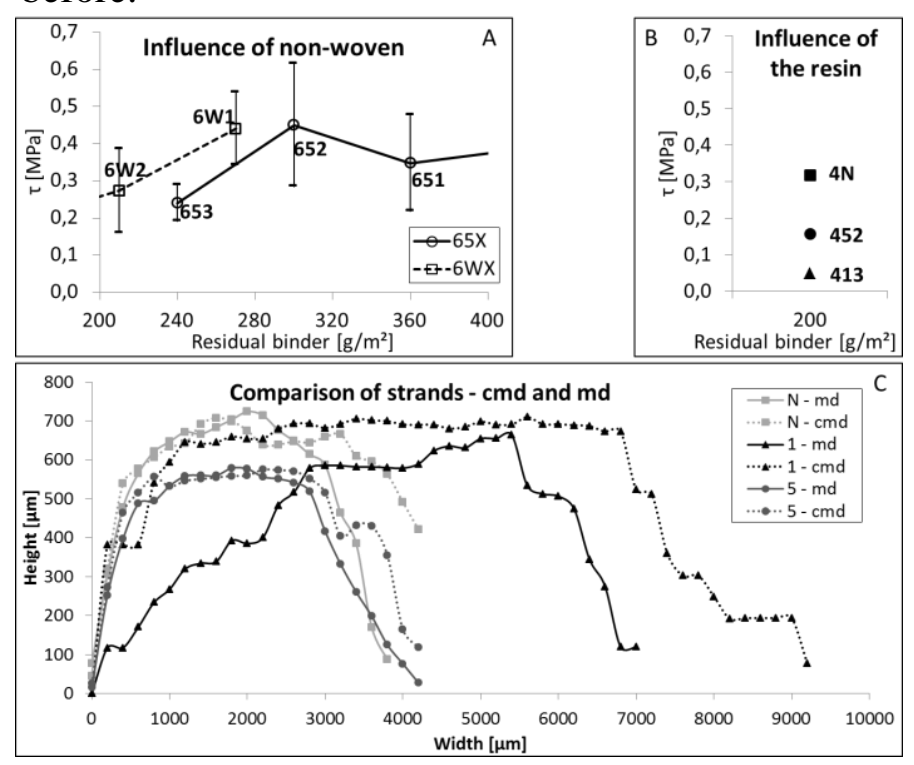

Figure 2. Influencing components on the bonding. A: Comparison of grids with and without non-woven, B: Comparison of grids with resin $\mathrm{A}$ and $\mathrm{B}, \mathrm{C}$ : Comparison of the shape of the strands

\section{MICROSCOPIC EXAMINATION}

The pictures of figure 3 were made with a 20times magnification and show about $1 \mathrm{~cm}$ of the interface width of 6 observed cores. Above the interlayer is the wearing course and below the binder course. The cores were cut perpendicular to the interlayer in the direction of rolling, the strands coming out of the cores are therefore filling yarns $(\mathrm{cmd})$. Because of the small amount of scanned specimens, the following pictures can only give an impression of the interlayer.

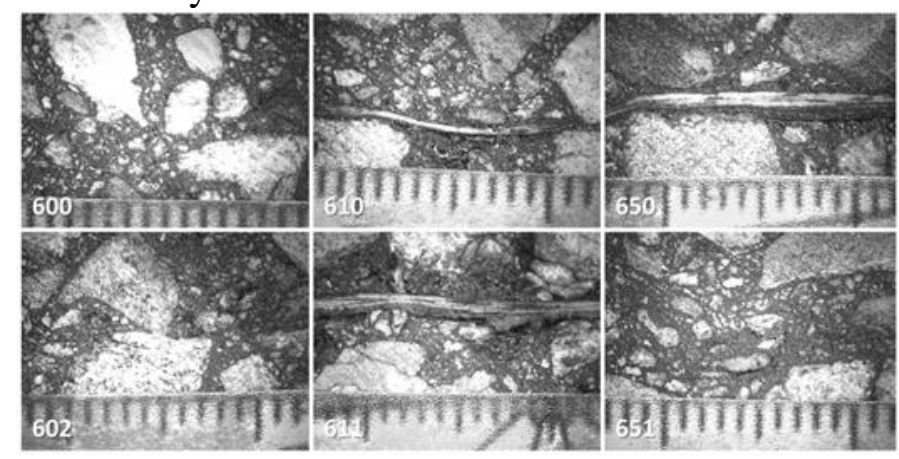

Figure 3. Results of the microscopic examination of the interfaces of cores from the sections $600,602,610,611,650$ and 651 with a 20times magnification

On the picture of the unreinforced specimens (600 and 602) we can see that the interface is not clearly visible between the wearing course and the binder course. This similarity in appearance is also visible in their test-results, as both achieve more than $1.1 \mathrm{MPa}$ average maximum shear stresses. No voids are visible for both samples.

The picture of 610,611 and 650 show a mdstrand running along the interface. On picture 610 the residual binder is clearly visible as a shining black part under the strand. On picture 611, we can observe one of the effects of the grid in the sample where voids, especially under the strands, are clearly visible. Traces of residual binder are also visible under the strands of picture 650 . For 650 as well as for 610 no voids are visible around the strand. All pictures show that the grid strands are able to move around the grains of the upper and lower layers.

Picture 651 shows a cmd-strands coming out of the core. Under this strand we see again a large void and around the strand, the interface is not clearly visible.

\section{INTERPRETATION OF THE RESULTS}

Because of their low shear stress results of the C40B5-S coated sections, they will not be further discussed.

As observed before, the unreinforced section group 60X shows a peak for an amount of $150 \mathrm{~g} / \mathrm{m}^{2}$ (application rate 2) of residual binder. The negative slope starting after this point is the expected result of 
the creation of a slip plane as mentioned before, due to the excess of residual binder. This new plane created between the upper and the lower courses of the structure appears to prevent a good interlocking between the granular of the upper and lower courses.

Knowing this, we can assume that the positive slope starting again from section $601\left(210 \mathrm{~g} / \mathrm{m}^{2}\right.$ of residual binder) and leading to section $600\left(816 \mathrm{~g} / \mathrm{m}^{2}\right.$ of residual binder) cannot be due to the interlocking between the aggregates as it is disturbed through the excess of residual binder, but only on the influence of the residual binder between the two layers. This loss of interlocking is visible in the slope of the curves, as the first ascension between 603 and 602 is greatly steeper than between 601 and 600, were the interlocking is strongly reduced.

Based on this result, a comparison was made between the average slope of the different section groups $61 \mathrm{X}, 65 \mathrm{X}$ and $6 \mathrm{WX}$, the group 603-602 (positive slope before the slip plane appears) and the group 601-600 (positive slope after the slip plane appeared). The average slopes of each group were calculated using the method of least squares and can be seen in figure 4 .

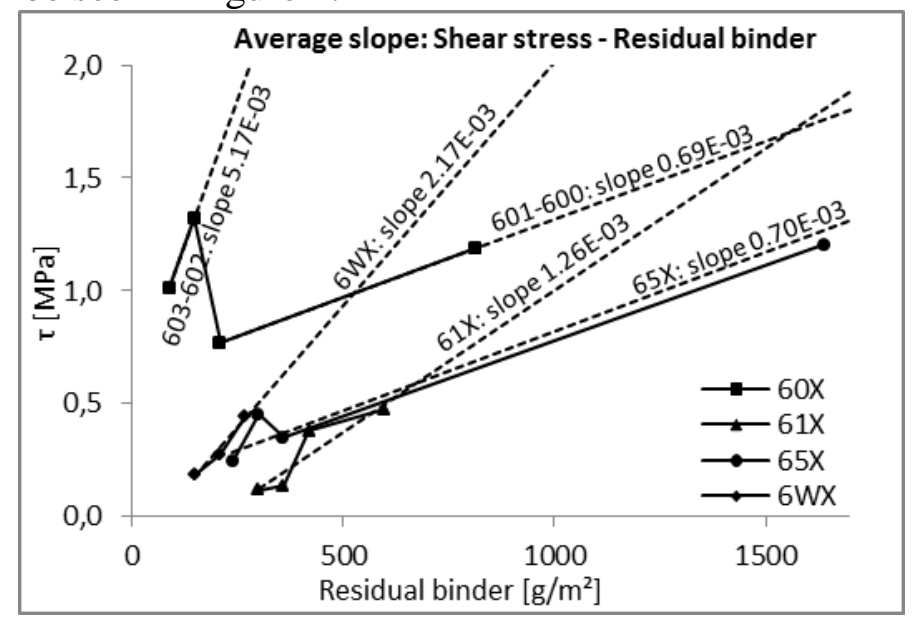

Figure 4. Average slope of each section group

The tendency described before can be observed again on this graph. The group 6WX using the grid W without non-woven shows the second steepest slope. Here the steep slope can be explained by the non-using of a non-woven, which enables a direct interlocking of the granular. However, as it was observed on the microscope picture, the grids strands are still disturbing the bonding by creating voids under the strands, explaining the difference of slope between the 6WX and 603-602 slopes. The supplement of residual binder fills the voids, explaining the nearly linear increase of the curve. Because of this possible interlocking, we can assume that with more residual binder, a slip plane will appear and cause a fall of the curve as happens on the unreinforced specimens curves.

The groups $61 \mathrm{X}$ and $65 \mathrm{X}$ show both flatter slopes, having both a non-woven between the strands of their grids. We assume that the interlocking of the aggregates is lightly disturbed through the non-woven, so that the main bonding agent is the adhesion through the residual binder. Here also the residual binder fills the voids under the strands of the grids, leading to better shear strength results. We observe that a great amount of residual binder as used for section 650 , leads to the maximum shear stress values equalling the best results of the unreinforced sections.

The representation of the curve as linear to infinity is clearly not correct. It is more likely that they will have a more rounded form at the beginning and will adjust to a maximum from a certain amount of residual binder. However the linearity of the curves is a good approximation for the middle part as represented.

\section{CONCLUSION}

This article studied the influence of glass fibre grids on interlayer bonding with experimental and numerical modelling.

For the experimental part, 28 different sections were built, varying types of grids (with and without nonwoven, different resins), types of emulsions and emulsion application rates. The 228 cylindrical cores extracted from the surface were tested with a monotonous shear test. The results were:

- The insertion of glass fibre grids has a negative influence on the bonding

- The application rate on reinforced samples has a great effect on the bonding. For low application rates, no positive influence on the shear stress is visible. However high application rates can lead to shear stresses similar to the ones of unreinforced samples.

- Important variations can be observed for different emulsion.

- The use of a non-woven between the strands leads to a loss of interlocking between the layers and so to lower shear stress results. For grids with non-woven a high application rate is greatly important but the temperature effect has to be checked due to the viscous behaviour of the bitumen.

- The resin with which the glass fibre are coated can have a positive influence on the bonding.

- The form of the strands can lead to a better interlocking between the grid and the upper layer.

\section{BIBLIOGRAPHY}

(Aresenie et al. 16) Arsenie, I. M., Chazallon, C., DUCHEZ, J. L., HORNYCH, P., "Laboratory characterisation of the fatigue behaviour of a glass fibre grid-reinforced asphalt concrete using 4PB tests", International Journal of 
Road Materials and Pavement Design, 2016,

DOI: 10.1080/14680629.2016.1163280.

(Canestrari et al. 2012) CANESTRARI, F., FERROTTI, G., Lu, X., Millien, A., Partl, M. N., Petit, C., Phelipot-Mardelé, A., Piber, H.,

RAAB, C., "Mechanical Testing of Interlayer Bonding in Asphalt Pavements", Volume 9 of the series RILEM State-of-the-Art Reports, 2012, p. 303-360.

(Nejad et al. 2014) NEJAD, F. M., NOORY, A., TOOLABI, S., FALlaH, S., "Effect of using geosynthetics on reflective crack prevention", International Journal of Pavement Engineering, 2014, Volume 16, Issue 6, p. 477487.

(Nguyen et al. 2013) NGUYEN, M.-L., BlANC, J., KERZRÉHO, J.-P., HORNYCH, P., "Review of glass fibre grid use for pavement reinforcement and APT experiments at IFSTTAR", Road Materials and Pavement Design, 2013, Volume 14, Sup 1, p. 287-308.

(Vismara et al. 2012) Vismara, S., MOLENAAR, A.A.A., CRISPINO, M., POOT, M.R., "Characterizing the Effects of Geosynthetics in Asphalt Pavements", $7^{\text {th }}$ RILEM International Conference on Cracking Pavements, 2012, p. 1199-1207, RILEM 2012.

(Sokolov 2007) SOKOLOv, K., "Laboruntersuchungen an unterschiedlich verstärkten Asphaltschichten", Tagung Asphaltverstärkungen mit Einlagen. Erfahrungen und Perspektiven, 15th May 2007 in Dübendorf. EMPAAkademie

(TP-A 2012) Forschungsgesellschaft für Straßenund Verkehrswesen (FGSV), Arbeitsgruppe "Asphaltbauweisen", "TP Asphalt StB, Teil 80: Abscherversuch", FGSV Nr 756/80, 2012, FGSV Verlag

(ZTV 2013) Forschungsgesellschaft für Straßen- und Verkehrswesen (FGSV), Arbeitsgruppe "Asphaltbauweisen", "ZTV Asphalt-StB”, FGSV Nr. 799, 2013, FGSV Verlag 